\title{
BMJ Open Cross-sectional association between cigarette smoking and abdominal obesity among Austrian bank employees
}

\author{
Lizia de Oliveira Fontes Gasperin, ${ }^{1}$ Manfred Neuberger, ${ }^{2}$ Alexander Tichy, ${ }^{3}$ \\ Hans Moshammer ${ }^{2}$
}

To cite: de Oliveira Fontes Gasperin L, Neuberger M, Tichy A, et al. Cross-sectional association between cigarette smoking and abdominal obesity among Austrian bank employees. BMJ Open 2014;4:e004899.

doi:10.1136/bmjopen-2014004899

- Prepublication history for this paper is available online. To view these files please visit the journal online (http://dx.doi.org/10.1136/ bmjopen-2014-004899).

Received 21 January 2014 Revised 15 June 2014 Accepted 27 June 2014

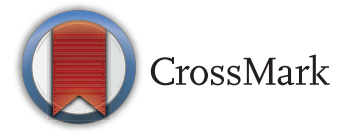

${ }^{1}$ Department of Nutritional Sciences, University of Vienna, Vienna, Austria ${ }^{2}$ Institute of Environmental Health, Medical University of Vienna, Vienna, Austria ${ }^{3}$ Platform Bioinformatics and Biostatistics, University of Veterinary Medicine, Vienna, Austria

Correspondence to Dr Hans Moshammer; hanns.moshammer@ meduniwien.ac.at

\section{ABSTRACT}

Objectives: There is increasing evidence that smoking is associated with abdominal obesity and other risk factors for the metabolic syndrome. The aim of this study is to investigate these associations in a sample of healthy Austrian adults.

Setting and participants: Data of 986 employees of an Austrian company (405 men and 581 women; participation rate approximately $80 \%$ ) obtained during their annual medical check-up at the workplace were analysed.

\section{Primary and secondary outcome measures:}

Information on smoking status, education level, physical activity, diet, body weight, height, body mass index (BMI), waist circumference and biochemical parameters was obtained. The influence of smoking on health and anthropometric measures was investigated.

Results: No differences in total body fat and/or body fat distribution were found between non-smokers, smokers and former smokers; however, among daily smokers, the number of cigarettes smoked per day was significantly associated with higher body weight $(p=0.001)$ and BMI $(p=0.009)$. Male and female smokers had significantly higher white cell count than non-smokers and former smokers. Heavy smokers also had an unhealthier lipid profile (lower high-density lipoprotein cholesterol) and higher fasting glucose levels even after controlling for physical activity and calorie intake.

Conclusions: Contrary to the beliefs of many smokers, heavy smoking is associated with higher body weight and unfavourable metabolic changes.

\section{INTRODUCTION}

In Austria, approximately 27\% of men and $19 \%$ of women aged 15 years and older are daily smokers. Whereas the smoking prevalence has decreased among men, it has increased among women and young people over the past 10 years. ${ }^{1}$ Obesity and overweight have also increased over the past decade, reaching epidemic proportions. ${ }^{2}$

\section{Strengths and limitations of this study}

- This is a cross-sectional study with all its inherent limitations.

- However, the study included many participants with a similar occupational and socioeconomic background and employed very detailed (and validated) questionnaires on diet and physical activity.

- Dietary information was thoroughly checked by nutritional experts.

- Dietary and smoking informations (as well as most data on body weight) were provided by self-report only.

- No information on alcohol consumption was available.

The combination of smoking with obesity further increases the mortality, particularly from circulatory diseases. ${ }^{3}$

Adolescents, especially girls, often believe that smoking is an effective tool for weight control. ${ }^{4}$ Similarly, smoking cessation has been associated with weight gain. ${ }^{5}$ However, weight loss in smokers does not necessarily reflect a decrease in the fat mass; rather, it may be caused by a reduction in the lean body mass ${ }^{6}$ and heavy smokers were found to have higher body weight than light smokers. ${ }^{7}$ Some studies reported that smoking is associated with abdominal obesity, ${ }^{7}$ which would favour the development of the metabolic syndrome, a cluster of risk factors for cardiovascular disease (CVD) and type 2 diabetes mellitus (T2DM) that includes central obesity, dyslipidaemia, hyperglycaemia and hypertension. ${ }^{8} 9$ Since other studies ${ }^{10}$ failed to find a positive association between cigarette smoking and abdominal obesity, this issue is still controversial and remains to be elucidated.

The aim of this cross-sectional study was to investigate whether cigarette smoking is 
associated with increased abdominal obesity and related metabolic changes in a sample of healthy Austrian adults.

\section{METHODS}

\section{Study population}

Participants were recruited among employees in a financial institution based in Vienna. Once a year the employees undergo a health screening at the company. After information on the purpose of the study and its procedures, they were invited to participate. Two days before the 2011 medical examination, they received a selfadministered questionnaire, which was collected on the examination day. Of the 1247 employees who filled in the questionnaires (participation rate: approximately $80 \%), 261$ were subsequently excluded: those who reported a history of cancer (20) or thyroid dysfunction (37), missing information on gender (3), age (1), anthropometric measurements (67), smoking status (80) and health status (24), pregnant women (3), individuals under nicotine replacement therapy at the time of the study (4), those with a body mass index (BMI) lower than $18.5 \mathrm{~kg} / \mathrm{m}^{2}$ or greater than $40 \mathrm{~kg} / \mathrm{m}^{2}$ (20) and those with a waist circumference (WC) lower than $60 \mathrm{~cm}$ (3). Data of 986 individuals (405 men and 581 women) aged 19-65 years were included in the final analyses. All participants signed an informed consent form and the study protocol was in accordance with the Declaration of Helsinki.

\section{Anthropometric measurements}

BMI was calculated as the ratio of weight in kilograms divided by the square of the height in metres $\left(\mathrm{kg} / \mathrm{m}^{2}\right)$. WC and hip circumferences (HC) were measured using a non-elastic flexible tape, with participants in light clothing without shoes: WC at the top of the right iliac crest, at the end of a normal expiration; $\mathrm{HC}$ at the largest posterior extension of the buttocks. ${ }^{11}$ Waist-to-hip ratio (WHR) was calculated as $\mathrm{WC} / \mathrm{HC}$, waist-to-height ratio $(\mathrm{WHtR})$ as $\mathrm{WC} /$ height.

\section{Lifestyle and education}

Participants who answered "no" to the following questions: "Have you ever smoked daily?", "Have you smoked at least 100 cigarettes, cigar, pipes or other tobacco products in your entire life?", "Do you smoke now?" were categorised as non-smokers. Individuals who reported smoking at the time of enrolment or quitted less than 1 year before were classified as smokers. Smokers included occasional $(<1$ cigarette per day) and daily smokers ( $\geq 1$ cigarette per day). Daily smokers were further subgrouped into light smokers (1-10 cigarettes per day), moderate smokers (11-20 cigarettes per day) and heavy smokers ( $>20$ cigarettes per day). Former smokers were defined as individuals who used to smoke and quitted at least 1 year prior to their recruitment.
Information on physical activity was obtained by the short form of the International Physical Activity Questionnaire (IPAQ). ${ }^{12}$ MET-minutes per week were then calculated according to the IPAQ scoring protocol, and participants were categorised into three PA levels: low, moderate and high. ${ }^{13}$ Dietary intake of food and beverages was obtained by means of self-administered $24 \mathrm{~h}$ recalls, supported by instructions and a validated photographic manual ${ }^{14}$ describing portion sizes.

Education was classified as 'low' for compulsory education (9 years of schooling in Austria), equivalent to levels 1 and 2 of the International Standard Classification of Education (ISCED), 'middle' for at least 3 years of additional schooling (ISCED levels 3 and 4) and 'high' for a university degree (ISCED levels 5 and 6 ).

\section{Blood samples}

Blood samples were taken by venipuncture after an overnight fast and collected into heparinised tubes. Complete blood count was performed automatically (Sysmex XT 2000i); fasting glucose (FG), total cholesterol (TC), high-density lipoprotein-cholesterol (HDL-C) and triacylglycerides (TAG) were also analysed by automated methods (Roche Modular, Roche Diagnostics, Vienna, Austria). Plasma low-density lipoproteincholesterol (LDL-C) was calculated using the Friedewald formula (LDL-C=TC-HDL-C-TAG/5) for TAG levels lower than $400 \mathrm{mg} / \mathrm{dL}^{15}$ Blood analyses were available for $88 \%$ of men and $91 \%$ of women.

\section{Statistical analyses}

Metric scaled variables are expressed as mean \pm SD. $\chi^{2}$ Tests were used to compare frequency distributions of categorical variables. Pearson's correlation coefficients were used to characterise relationships between BMI and WC. For univariate analyses, factor levels were compared using the least significant difference (LSD) post hoc procedure.

Multivariate analyses of variances (MANOVA) were performed to evaluate the impact of smoking status or number of cigarettes on anthropometric and biochemical parameters. Comparisons between non-smokers, smokers and former smokers were performed separately for men and women. Smoking status and level of education were used as fixed factors. In models where the number of cigarettes per day was used, gender was added as a fixed factor.

Several general linear models were used to evaluate the influence of possible confounders in the results. The level of complexity was increased stepwise by adding specific variables such as age, physical activity level and total energy intake as covariates to the model. The result of the simplest model is presented, when $\mathrm{p}$ values remained unchanged after correcting for the different covariates.

For all analyses a two-tailed $\mathrm{p}$ value less than $5 \%$ $(p<0.05)$ was considered statistically significant. All statistical analyses were performed using the IBM SPSS V.20 (SPSS Inc, Chicago, Illinois, USA). 
In the linear regression models, 'number of cigarettes' was included as a categorical variable. When visual inspection indicated deviance from linearity, a general additive model using splines with 4 degrees of freedom for the number of cigarettes per day was tested. The latter analyses were performed with STATA SE V.12.1 (StataCorp, College Station, Texas, USA).

\section{RESULTS}

Smokers of both sexes were younger than non-smokers and former smokers. Among men, the average ages of non-smokers, smokers and former smokers were $43 \pm 9.5$, $38.3 \pm 10.8$ and $45.9 \pm 8.2$ years, respectively. Differences between the three groups were statistically significant (non-smokers vs smokers: $\mathrm{p}<0.001$; non-smokers vs former smokers: $\mathrm{p}=0.016$; smokers vs former smokers: $\mathrm{p}<0.001)$. Among women, non-smokers, smokers and former smokers aged on average 40.5 $\pm 8.7,37.6 \pm 10.1$ and 42.4 \pm 8.5 years, respectively. Smokers differed significantly from non-smokers $(p=0.001)$ and former smokers $(p<0.001)$.

The baseline characteristics of the participants, according to gender and smoking status, are presented in table 1 for men and in table 2 for women. There were only few participants (five men and nine women) with a low level of education, and therefore the low and medium levels were combined.

The anthropometric indices were highly correlated in men and women. Among men, $67.4 \%$ of the variance in BMI was explained by WC $(\mathrm{r}=0.82, \mathrm{p}<0.001)$. Among women, $68.7 \%$ of the variance in BMI was accounted for by WC $(r=0.83, p<0.001)$. In the whole sample (men and women together), Pearson's correlation between WHR and BMI was $r=0.46$, between WHtR and BMI was $r=0.82$, between WHR and body weight was $r=0.54$, and between WHtR and body weight was $r=0.71(p<0.001$ for all correlations).

Among men and women, no statistically significant differences were found between the three smoking groups regarding the anthropometric indices. The results did not change after excluding occasional smokers $(<1$ cigarette per day) from the group of smokers (data not shown).

Among men and women, FG, TC, LDL-C, ratio of TC to HDL-C and LDL-C did not differ significantly between non-smokers, smokers and former smokers, after controlling for age, physical activity and energy intake.

Among men, the total white cell counts (WCCs) were significantly elevated in smokers, compared with nonsmokers $(p<0.001)$ and former smokers $(p<0.001)$. The

Table 1 Baseline characteristics of male participants according to the smoking status

\begin{tabular}{|c|c|c|c|c|}
\hline & Non-smokers & Smokers & Former smokers & p Value \\
\hline Sample size, n (\%) & $180(44.4)$ & $122(30.1)$ & $103(25.4)$ & \\
\hline Age, years & $43.0 \pm 9.5$ & $38.3 \pm 10.8$ & $45.9 \pm 9.2$ & 0.032 \\
\hline Height, cm & $179.8 \pm 5.9$ & $179 \pm 5.7$ & $179 \pm 7.1$ & $0.560^{*}$ \\
\hline Body weight, kg & $81.3 \pm 10.9$ & $81.5 \pm 11.9$ & $83.7 \pm 11.2$ & $0.777^{*}$ \\
\hline $\mathrm{BMI}, \mathrm{kg} / \mathrm{m}^{2}$ & $25.1 \pm 3.0$ & $25.3 \pm 3.3$ & $26.1 \pm 3.5$ & $0.634^{*}$ \\
\hline $\mathrm{WC}, \mathrm{cm}$ & $92.2 \pm 9.5$ & $92.1 \pm 10.1$ & $94.6 \pm 9.4$ & $0.911^{*}$ \\
\hline $\mathrm{HC}, \mathrm{cm}$ & $99.0 \pm 7.4$ & $98.6 \pm 7.2$ & $99.7 \pm 7.6$ & $0.895^{\star}$ \\
\hline WHR & $0.931 \pm 0.07$ & $0.932 \pm 0.06$ & $0.950 \pm 0.08$ & $0.466^{*}$ \\
\hline WHtR & $0.524 \pm 0.06$ & $0.520 \pm 0.06$ & $0.540 \pm 0.06$ & $0.827^{*}$ \\
\hline Fasting glucose, mmol & $4.6 \pm 0.6$ & $4.5 \pm 1.0$ & $4.6 \pm 0.5$ & $0.217^{*}$ \\
\hline Total cholesterol, $\mathrm{mmol}$ & $5.6 \pm 1.0$ & $5.5 \pm 1.1$ & $5.6 \pm 0.9$ & $0.683^{*}$ \\
\hline HDL-C, mmol & $1.4 \pm 0.3$ & $1.4 \pm 0.4$ & $1.5 \pm 0.3$ & $0.025^{\star}$ \\
\hline LDL-C, mmol & $3.6 \pm 0.9$ & $3.5 \pm 0.9$ & $3.6 \pm 0.8$ & $0.990^{*}$ \\
\hline Triacylglycerols, mmol & $1.3 \pm 0.7$ & $1.5 \pm 1.0$ & $1.4 \pm 1.0$ & $0.006^{*}$ \\
\hline TC to HDL-C ratio & $4.2 \pm 1.2$ & $4.3 \pm 1.3$ & $4.1 \pm 1.2$ & $0.098^{*}$ \\
\hline Total WCC, G/L ${ }^{(a, b)}$ & $6.2 \pm 1.4$ & $7.1 \pm 1.9$ & $6.3 \pm 1.2$ & $0.009^{\star}$ \\
\hline Energy intake, kJ & $9306 \pm 2334$ & $9402 \pm 1865$ & $9411 \pm 2355$ & $0.941 \dagger$ \\
\hline \multicolumn{5}{|l|}{ Physical activity (\%) } \\
\hline Low & 33.5 & 33.0 & 29.1 & $0.902 \ddagger$ \\
\hline Medium & 46.5 & 48.9 & 47.7 & \\
\hline High & 20.0 & 18.1 & 23.3 & \\
\hline \multicolumn{5}{|l|}{ Education level } \\
\hline Medium & 56.9 & 77.0 & 74.5 & $<0.001 \ddagger$ \\
\hline High & 43.1 & 23.0 & 25.5 & \\
\hline
\end{tabular}

Values are shown as mean \pm SD.

*p Value determined by multivariate ANOVA and adjusted for age, physical activity and energy intake.

$t p$ Value determined by multivariate ANOVA and adjusted for age. LSD was the post hoc procedure. (a) Statistically significant differences between non-smokers and smokers and (b) statistically significant differences between smokers and former smokers. $\neq \mathrm{p}$ Values analysed using $\chi^{2}$ test.

BMI, body mass index; G/L, $1 \times 10^{9}$ cells/L. HC, hip circumference; HDL-C, high-density lipoprotein cholesterol; LDL-C, low-density lipoprotein cholesterol; WC, waist circumference; WCC, white cell count; WHR, waist-to-hip ratio; WHtR, waist-to-height ratio. 
Table 2 Baseline characteristics of female participants according to the smoking status

\begin{tabular}{|c|c|c|c|c|}
\hline & Non-smokers & Smokers & Former smokers & p Value \\
\hline Sample size, n (\%) & $276(47.5)$ & $181(31.2)$ & $124(21.3)$ & \\
\hline Age, years & $40.5 \pm 8.7$ & $37.6 \pm 10.1$ & $42.4 \pm 8.5$ & 0.256 \\
\hline Height, cm & $166.8 \pm 5.7$ & $166.3 \pm 6.0$ & $167.6 \pm 5.7$ & $0.246^{*}$ \\
\hline Body weight, kg & $65.6 \pm 11.0$ & $65.3 \pm 10.4$ & $68.1 \pm 12.7$ & $0.610^{*}$ \\
\hline $\mathrm{BMI}, \mathrm{kg} / \mathrm{m}^{2}$ & $23.6 \pm 3.8$ & $23.6 \pm 3.4$ & $24.2 \pm 4.2$ & $0.637^{*}$ \\
\hline $\mathrm{WC}, \mathrm{cm}$ & $83.4 \pm 10.2$ & $83.4 \pm 9.9$ & $85.2 \pm 12.7$ & $0.467^{*}$ \\
\hline $\mathrm{HC}, \mathrm{cm}$ & $97.2 \pm 9.5$ & $96.6 \pm 8.6$ & $98.1 \pm 11.4$ & $0.857^{*}$ \\
\hline WHR & $0.858 \pm 0.06$ & $0.863 \pm 0.06$ & $0.867 \pm 0.06$ & $0.332^{*}$ \\
\hline WHtR & $0.494 \pm 0.06$ & $0.499 \pm 0.06$ & $0.505 \pm 0.08$ & $0.374^{*}$ \\
\hline Fasting glucose, mmol & $4.4 \pm 0.9$ & $4.3 \pm 0.7$ & $4.4 \pm 0.7$ & $0.097^{*}$ \\
\hline Total cholesterol, $\mathrm{mmol}$ & $5.5 \pm 1.0$ & $5.4 \pm 1.0$ & $5.4 \pm 0.9$ & $0.318^{*}$ \\
\hline HDL-C, mmol & $1.8 \pm 0.4$ & $1.7 \pm 0.4$ & $1.8 \pm 0.4$ & $0.177^{*}$ \\
\hline LDL-C, mmol & $3.2 \pm 0.9$ & $3.3 \pm 0.9$ & $3.2 \pm 0.8$ & $0.510^{*}$ \\
\hline Triacylglycerols, mmol & $1.0 \pm 0.4$ & $1.1 \pm 0.6$ & $1.0 \pm 0.4$ & $0.448^{*}$ \\
\hline TC to HDL-C ratio & $3.1 \pm 0.8$ & $3.5 \pm 1.1$ & $3.2 \pm 0.8$ & $0.083^{*}$ \\
\hline Total WCC, G/L ${ }^{(a, b)}$ & $6.4 \pm 1.5$ & $7.7 \pm 2.1$ & $6.3 \pm 1.8$ & $<0.001^{*}$ \\
\hline Energy intake, kJ & $7647 \pm 1777$ & $6989 \pm 1806$ & $7383 \pm 1999$ & $0.008 \dagger$ \\
\hline \multicolumn{5}{|l|}{ Physical activity (\%) } \\
\hline Low & 33.3 & 26.5 & 24.2 & $0.019 \ddagger$ \\
\hline Medium & 43.5 & 60.3 & 52.6 & \\
\hline High & 23.1 & 13.2 & 23.2 & \\
\hline \multicolumn{5}{|l|}{ Education level (\%) } \\
\hline Medium & 75.3 & 90 & 82.3 & $<0.001 \ddagger$ \\
\hline High & 24.7 & 10 & 17.1 & \\
\hline
\end{tabular}

Values are shown as mean \pm SD

${ }^{*} p$ Value determined by multivariate ANOVA and adjusted for age, physical activity and energy intake.

tp Value determined by multivariate ANOVA and adjusted for age. LSD was the post hoc procedure. (a) Statistically significant differences between non-smokers and smokers and (b) statistically significant differences between smokers and former smokers.

$\ddagger \mathrm{p}$ Values analysed using $\chi^{2}$ test.

BMI, body mass index; G/L, $1 \times 10^{9}$ cells/L. HC, hip circumference; HDL-C, high-density lipoprotein cholesterol; LDL-C, low-density lipoprotein cholesterol; TC, total cholesterol; WC, waist circumference; WCC, white cell count; WHR, waist-to-hip ratio; WHtR, waist-to-height ratio.

differences between the groups remained statistically significant after controlling for age, physical activity and energy intake (table 1).

Among women, the total WCC were significantly higher in smokers, compared with non-smokers $(\mathrm{p}<0.001)$ and former smokers $(\mathrm{p}<0.001)$, and the differences remained significant after controlling for confounders. No differences in the total or differential WCCs were found between female non-smokers and female former smokers (table 2).

\section{Characteristics of daily smokers, according to the number of cigarettes smoked per day}

The mean \pm SD number of cigarettes per day was $6.3 \pm 3.3$ for light smokers, $17.3 \pm 2.8$ for moderate smokers and 28.8 \pm 5.5 for heavy smokers.

The mean $\pm \mathrm{SD}$ ages of light smokers, moderate smokers and heavy smokers were $37 \pm 10.7,39.3 \pm 10.2$ and $43.8 \pm 7.4$, respectively. Heavy smokers were significantly older than light smokers $(p=0.023)$. No significant differences in the average age at which participants started smoking were observed between the groups. However, they differed significantly $(p=0.020)$ regarding the years of smoking (light smokers: 18.9 \pm 9.8 years; moderate smokers: $21.8 \pm 9.9$ years; heavy smokers: $24.7 \pm 7.3$ years).
The characteristics of daily smokers, according to the number of cigarettes smoked per day, are shown in table 3.

In the unadjusted model, heavy smokers had significantly greater values of body weight $(\mathrm{p}=0.030)$, BMI $(\mathrm{p}=0.003)$, WC $(\mathrm{p}=0.032)$ and HC $(\mathrm{p}=0.036)$ than light and moderate smokers. After controlling for age, physical activity and energy intake, the significance remained only for body weight $(\mathrm{p}=0.009)$ and BMI $(\mathrm{p}=0.023)$.

Overweight and obesity were observed in $84.6 \%$ of heavy smokers, compared with $35.6 \%$ of light smokers and $33 \%$ of moderate smokers $\left(\chi^{2}=13.5, \mathrm{p}=0.001\right)$.

The results of the linear regression models for selected end points are shown in table 4 including also the impact of physical activity (low, moderate and high activity level), reported consumption of calories, education, age and gender. A non-linear association for the numbers of cigarettes was evident for body weight, TAG, HDL-C and FG (figure 1) with strong adverse effects usually only seen in heavy smokers.

\section{DISCUSSION}

In the present study, no statistical differences in the mean values of body weight and BMI were found between non-smokers, smokers and former smokers. 
Table 3 Baseline characteristics of daily smokers, according to the smoking intensity

\begin{tabular}{|c|c|c|c|c|}
\hline & \multicolumn{4}{|l|}{ Smoking intensity } \\
\hline & Light smokers $(\mathrm{n}=135)$ & Moderate smokers $(n=106)$ & Heavy smokers $(n=13)$ & p Value \\
\hline Body weight, $\mathrm{kg}^{(\mathrm{b}, \mathrm{c})}$ & $71.3 \pm 13.6$ & $70.8 \pm 12.8$ & $81.3 \pm 18.0$ & 0.009 \\
\hline BMI, $\mathrm{kg} / \mathrm{m}^{2(\mathrm{~b}, \mathrm{c})}$ & $24.2 \pm 3.5$ & $24.1 \pm 3.5$ & $27.5 \pm 3.4$ & 0.023 \\
\hline $\mathrm{WC}, \mathrm{cm}$ & $86.0 \pm 11.4$ & $86.9 \pm 10.2$ & $94.3 \pm 11.7$ & 0.059 \\
\hline $\mathrm{HC}, \mathrm{cm}$ & $96.5 \pm 8.6$ & $97.7 \pm 8.0$ & $102.6 \pm 8.5$ & 0.163 \\
\hline WHR & $0.890 \pm 0.08$ & $0.890 \pm 0.07$ & $0.920 \pm 0.07$ & 0.280 \\
\hline WHtR & $0.502 \pm 0.06$ & $0.508 \pm 0.06$ & $0.545 \pm 0.05$ & 0.266 \\
\hline $\mathrm{FG}, \mathrm{mmol}^{(\mathrm{b}, \mathrm{c})}$ & $4.3 \pm 0.6$ & $4.4 \pm 0.8$ & $5.3 \pm 2.6$ & 0.010 \\
\hline $\mathrm{TC}, \mathrm{mmol}$ & $5.4 \pm 1.1$ & $5.4 \pm 1.0$ & $5.6 \pm 0.7$ & 0.399 \\
\hline HDL-C, mmol & $1.6 \pm 0.4$ & $1.5 \pm 0.4$ & $1.1 \pm 0.3$ & 0.057 \\
\hline LDL-C, $\mathrm{mmol}$ & $3.3 \pm 1.1$ & $3.3 \pm 0.9$ & $3.6 \pm 0.6$ & 0.515 \\
\hline TC to HDL-C ratio ${ }^{(b, c)}$ & $3.6 \pm 1.2$ & $3.9 \pm 1.2$ & $5.5 \pm 1.8$ & 0.033 \\
\hline $\mathrm{TAG} \mathrm{mmol}^{(\mathrm{b}, \mathrm{c})}$ & $1.1 \pm 0.6$ & $1.3 \pm 0.7$ & $2.5 \pm 1.9$ & 0.006 \\
\hline Total WCC, G/L & $7.0 \pm 1.8$ & $8.0 \pm 2.3$ & $8.0 \pm 2.2$ & 0.035 \\
\hline \multicolumn{5}{|c|}{$\begin{array}{l}\text { Values are shown as mean } \pm \text { SD. } \\
\text { p Value determined by multivariate ANOVA and adjusted for age, physical activity and energy intake; LSD was the post hoc procedure; (a) } \\
\text { statistically significant differences between light and moderate smokers; (b) statistically significant differences between light and heavy } \\
\text { smokers; (c) statistically significant differences between moderate and heavy smokers. Light smokers: } 1-10 \text { cigarettes per day; moderate } \\
\text { smokers: } 11-20 \text { cigarettes per day; heavy smokers: }>20 \text { cigarettes per day. } \\
\text { BMI, body mass index; FG, fasting glucose; HC, hip circumference; HDL-C, high-density lipoprotein cholesterol; LDL-C, low-density } \\
\text { lipoprotein cholesterol; TAG, triacylglycerols; TC, total cholesterol; WC, waist circumference; WCC, white cell count; WHR, waist-to-hip ratio; } \\
\text { WHtR, waist-to-height ratio. }\end{array}$} \\
\hline
\end{tabular}

Likewise, no statistically significant differences in the patterns of abdominal obesity-assessed by WC, WHR or $\mathrm{WHtR}$ - were found between three groups.

However, among male participants, physical activity was found to be negatively and independently associated with body weight, BMI, WC, WHR and WHtR, after controlling for age, smoking and energy intake (data not shown). Previous studies have also reported an independent association between activity scores and body fat distribution among European men, after adjustment for smoking. ${ }^{16}$

Although several studies found that smokers have lower body weight and BMI than non-smokers, ${ }^{17} 18$ the results in the literature are inconclusive. Our data are in accordance with those of previous studies which found no significant differences between smokers and nonsmokers regarding those anthropometric indices. ${ }^{19} 20$ Different from other findings ${ }^{21-23}$ and in agreement with others, ${ }^{24} 25$ in our study smoking status was not significantly associated with increased abdominal obesity.

Smoking cessation is often accompanied by weight gain, especially among heavy smokers. ${ }^{5}{ }^{26}$ In the present study, former smokers were not found to have significantly higher body weight or BMI than non-smokers or smokers. Recent quitters in this study were not included among former smokers. So this study at least indicates that any weight gain after smoking cessation is not permanent.

While smoking status per se had only little effect on anthropometric parameters, heavy smokers (>20 cigarettes per day) had significantly higher values of body weight and BMI, compared with light (1-10 cigarettes per day) and moderate (11-20 cigarettes per day) smokers. The significance remained even after controlling for age, physical activity and energy intake.

The possible explanations for a higher body weight/ BMI among heavy smokers, compared with light smokers, are differences in personality ${ }^{27}$ and some lifestyle characteristics ${ }^{28}$ that may increase their risk of becoming overweight and obese. ${ }^{29}$ They were reported to consume more alcohol, be less active and have a poorer diet, compared with light and moderate smokers. ${ }^{30}$ It is possible that the higher consumption of alcohol among heavy smokers leads to a weight gain which is not observed in light and moderate smokers. ${ }^{31}$

Regarding the laboratory analyses, differences in the lipid profile, according to the smoking status, were found only in men, after controlling for age, physical activity and energy intake. In women, although the analyses were not controlled for menstrual cycle, controlling for the use of hormonal contraceptive or hormonal replacement therapy did not change the results (data not shown). Male smokers presented higher levels of TAG and lower levels of HDL-C. Effects of smoking were generally more pronounced in heavy smokers. In addition, the levels of FG increased significantly with the number of cigarettes smoked per day, and the significance remained after controlling for age, physical activity and energy intake.

Overall, neither smoking status nor smoking intensity was positively associated with the levels of $\mathrm{TC}$ or LDL-C. These serum lipid parameters seem to be little influenced by smoking. ${ }^{32}$ However, other authors found a clear association of cigarette smoking with low levels of TC and LDL-C. ${ }^{33}$ In the present study, lower levels of HDL-C were associated with smoking status in men after 
Table 4 Results of the multiple linear regressions (also controlled for age and education, not shown)

\begin{tabular}{|c|c|c|c|c|c|c|c|}
\hline Coefficient & $\begin{array}{l}\text { Body } \\
\text { weight, kg }\end{array}$ & $\begin{array}{l}\text { BMI, } \\
\mathrm{kg} / \mathrm{m}^{2}\end{array}$ & WC, $\mathrm{cm}$ & $\begin{array}{l}\text { Total } \\
\text { WCC, G/L }\end{array}$ & $\begin{array}{l}\text { Fasting } \\
\text { glucose, mmol }\end{array}$ & HDL-C, mmol & TAG, mmol \\
\hline Females & -5.3 & -0.7 & -4.3 & 0.5 & -0.18 & 0.35 & -0.32 \\
\hline Body height, cm & 0.8 & NA & 0.3 & NA & NA & NA & NA \\
\hline Occasional smokers & -0.3 & -0.2 & -0.9 & 0.1 & -0.03 & -0.05 & 0.05 \\
\hline Light smokers & 0.2 & -0.1 & -0.2 & 0.6 & -0.09 & -0.12 & 0.11 \\
\hline Moderate smokers & -1.3 & -0.2 & -0.9 & 1.3 & -0.04 & -0.13 & 0.13 \\
\hline Heavy smokers & 9.5 & 3.5 & 7.1 & 1.7 & 0.74 & -0.55 & 0.85 \\
\hline Moderate physical activity & -1.0 & -0.5 & -0.5 & -0.8 & - & 0.04 & -0.09 \\
\hline High physical activity & -3.4 & -1.2 & -2.8 & -0.8 & - & 0.12 & -0.14 \\
\hline Calories, kJ/day & 10.5 & 3.4 & 8.4 & 1.7 & 0.4 & -0.2 & 0.1 \\
\hline
\end{tabular}

Occasional smokers, less than 1 cigarette per day; light smokers, 1-10 cigarettes per day; moderate smokers, 11-20 cigarettes per day; heavy smokers: $>20$ cigarettes per day. All smoking categories compared to non-smokers. Bold coefficients: $p<0.01$; italic coefficients: $\mathrm{p}<0.05$. NA, not applicable (body height in the case of BMI and lab parameters); - , dropped from the model.

BMI, body mass index; HDL-C, high-density lipoprotein cholesterol; TAG, triacylglycerides; WC, waist circumference; WCC, white cell count.

controlling for several confounders. Also, the number of cigarettes smoked as well as pack years (data not shown) was significantly and negatively correlated with HDL-C.

With respect to the levels of FG, no differences were observed between smokers, non-smokers and former smokers. However, heavy smokers ( $>20$ cigarettes per day) showed significantly higher levels of FG compared with light and moderate smokers. The significance persisted after controlling for age, physical activity and energy intake. The absolute mean values of fasting glucose increased in a graded manner according to the smoking intensity. These findings are of relevance because in a large number of prospective studies cigarette smoking has been associated with a higher risk of T2DM, ${ }^{34}$ especially in heavy smokers. ${ }^{35}$
The crude and adjusted mean values of total and differential WCCs were significantly higher in male and female smokers, compared with their non-smoking and former smoking counterparts. No differences were observed between non-smokers and former smokers, indicating a decrease in the WCC after smoking cessation, close to the levels found in never-smokers. Signs of inflammation in smokers are maybe not surprising considering the strong inflammatory impact on the airways. However, systemic inflammatory diseases are also associated with smoking. ${ }^{36}$

When smokers were categorised according to the number of cigarettes smoked per day, statistically significant differences in the total WCCs were found between light and moderate smokers, after controlling for
Figure 1 (A) Non-linear

influence of cigarettes smoked per day on body weight, results of general additive model, spline function with 4 degrees of freedom. (B) Non-linear influence of cigarettes smoked per day on triacylglycerols, results of general additive model, spline function with 4 degrees of freedom. (C) Non-linear influence of cigarettes smoked per day on high-density lipoprotein cholesterol, results of general additive model, spline function with 4 degrees of freedom. (D) Non-linear influence of cigarettes smoked per day on fasting glucose, results of general additive model, spline function with 4 degrees of freedom.
A

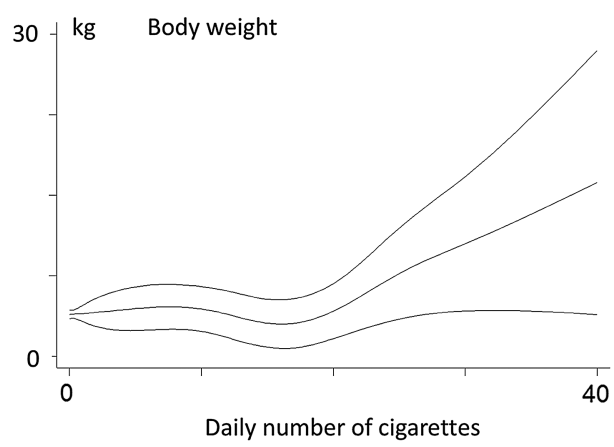

C

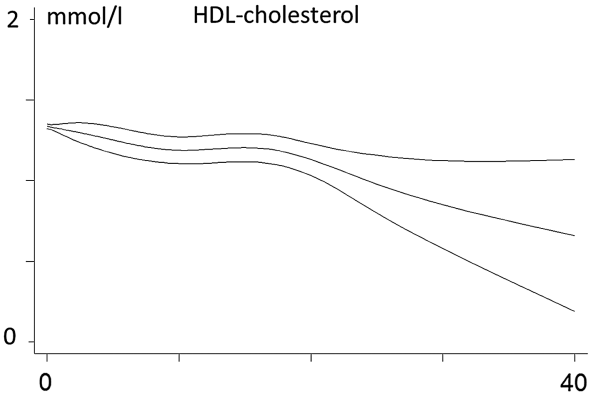

Daily number of cigarettes
B

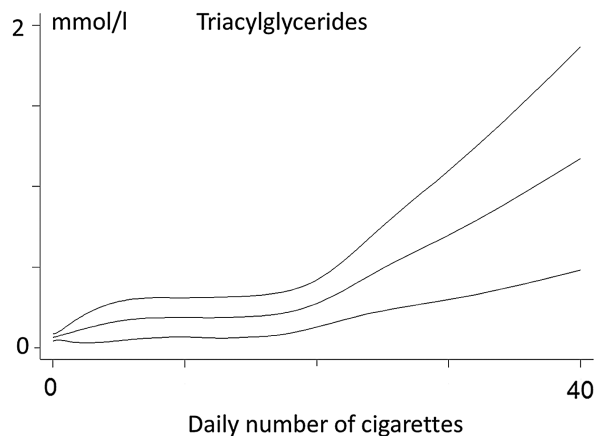

D

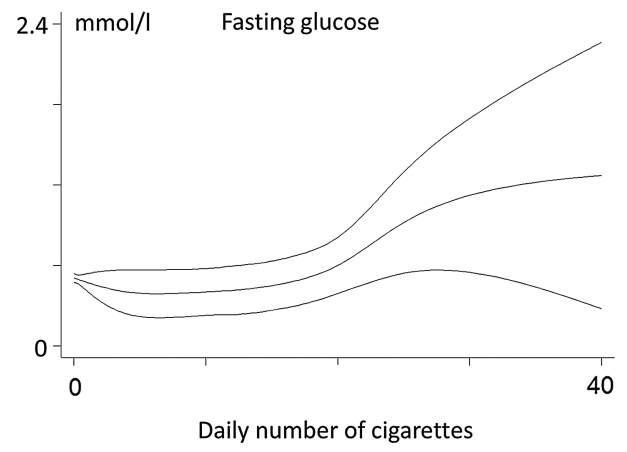


confounders. Although no significant differences were found between light and heavy smokers, it is important to observe that the absolute differences between the means of the WCCs in light and moderate smokers were the same as that between light and heavy smokers. The latter has not achieved statistical significance probably due to the small number of heavy smokers in the sample, in comparison to light and moderate smokers.

Cigarette smoking is a well-known risk factor for atherosclerosis and CVD, as discussed before, and it has been recognised as the single most important factor known to influence the WCC. ${ }^{37}$ The WCC has been correlated with CVD and is considered a biomarker of inflammatory processes that contribute to endothelial dysfunction and atherosclerosis progression. ${ }^{38}$

This study has strengths and limitations. The strengths are the large sample size with a wide age range (1965 years) and the use of validated questionnaires for the assessment of smoking status and lifestyle-including diet, education level and physical activity. Therefore, adjustment for important confounders could be performed.

The limitations were the cross-sectional design of the study-which does not allow one to infer about cause and effect-and the use of self-reported weight and height as a routine in annual health check-ups, which were controlled by measurement only if deviant from earlier data, however, which could introduce bias to the study. Studies have demonstrated the validity and reliability of self-reported height and weight in different study populations. ${ }^{39}$ Moreover, self-reported BMI and measured WC were highly correlated in the present study, which suggests good quality of the present data.

Acknowledgements The authors would like to gratefully acknowledge the helpful co-operation of the employees under study and the support from the occupational health department of their institution. The thesis work was guided and supported by Dr Ibrahim Elmadfa, director and professor, Institute of Nutritional Sciences, University of Vienna.

Contributors LdOFG collected and sorted the data as part of her thesis work. The thesis paper formed the key basis of this paper. AT helped her with the statistical analysis. MN advised her with the original study concept and later helped her to formulate the paper. This was partly a task of rewording and of shortening the original thesis. Thesis papers tend to be rather long and turning this into a paper fit for a journal is a rather tough job. HM did additional statistical analyses (regression analyses, GAM) and also helped with the wording and the submission work.

Funding This research received no specific grant from any funding agency in the public, commercial or not-for-profit sector.

Competing interests None.

Ethics approval Ethical Commission of the City of Vienna.

Provenance and peer review Not commissioned; externally peer reviewed.

Data sharing statement The raw data (Excel file) and additional analyses results are available on email request (hanns.moshammer@meduniwien.ac.at).

Open Access This is an Open Access article distributed in accordance with the Creative Commons Attribution Non Commercial (CC BY-NC 3.0) license, which permits others to distribute, remix, adapt, build upon this work noncommercially, and license their derivative works on different terms, provided the original work is properly cited and the use is non-commercial. See: http:// creativecommons.org/licenses/by-nc/3.0/

\section{REFERENCES}

1. Statistik Austria. Österreichische Gesundheitsbefragung 2006/2007: Bundesanstalt Statistik Österreich 2007. Wien, Austria. http://www. statistik.at/web_de/dynamic/statistiken/gesundheit/publdetail? $\mathrm{id}=4$ \&listid $=4 \&$ detail=457 (accessed 15 Nov 2011).

2. Elmadfa I. European Nutrition and Health Report 2009. Forum Nutr. 62. http://www.univie.ac.at/enhr/downloads/enhrii_book.pdf (accessed 24 Nov 2011).

3. Shinton R. Lifelong exposures and the potential for stroke prevention: the contribution of cigarette smoking, exercise, and body fat. J Epidemiol Community Health 1997;51:138-43.

4. White MA. Smoking for weight control and its associations with eating disorder symptomatology. Compr Psychiatry 2012; 53:403-7.

5. Filozof C, Fernández Pinilla MC, Fernández-Cruz A Smoking cessation and weight gain. Obes Rev 2004;5:95-103.

6. Canoy D, Wareham N, Luben R, et al. Cigarette smoking and fat distribution in 21,828 British men and women: a population-based study. Obes Res 2005;13:1466-75.

7. Chiolero A, Faeh D, Paccaud F, et al. Consequences of smoking for body weight, body fat distribution, and insulin resistance. Am J Clin Nutr 2008;87:801-9.

8. Rocha E. Metabolic syndrome: what is it and how useful is the diagnosis in clinical practice? Rev Port Cardiol 2012;31:637-9.

9. Sun K, Liu J, Ning G. Active smoking and risk of metabolic syndrome: a meta-analysis of prospective studies. PLOS ONE 2012;7:e47791.

10. Niskanen L, Laaksonen DE, Nyyssönen K, et al. Inflammation, abdominal obesity, and smoking as predictors of hypertension. Hypertension 2004;44:859-65.

11. Obesity Education Initiative. The practical guide. Identification, evaluation, and treatment of overweight and obesity in adults. NIH publication number 00-4084. National Institutes of Health, NHLBI Obesity Education Initiative, National Heart, Lung, and Blood Institute, North American Association for the Study of Obesity. October 2000. http://www.nhlbi.nih.gov/guidelines/obesity/prctgd_c. pdf (accessed 16 Aug 2013).

12. Craig CL, Marshall AL, Sjöström M, et al. International physical activity questionnaire: 12 -country reliability and validity. Med Sci Sports Exerc 2003;35:1381-95.

13. IPAQ-International Physical Activity Questionnaire. Guidelines for the data processing and analysis of the International Physical Activity Questionnaire 2005. http://www.ipaq.ki.se/scoring.pdf (accessed 23 Nov 2011)

14. Himmerich $\mathrm{S}$, Gedrich $\mathrm{K}$, Himmerich $\mathrm{H}$, et al. Die Bayerische Verzehrsstudie BVS II: Methodik und erste Ergebnisse. Proceedings of the German Nutrition Society, 2004-Abstracts zum 41. Wissenschaftlichen Kongress der Deutschen Gesellschaft für Ernährung DGE 6; 82. http://www.vis.bayern.de/ernaehrung/ ernaehrung/ernaehrungssituation/doc/abschlussbericht_bvs2.pdf (accessed 14 May 2013).

15. Friedewald WT, Levy RI, Fredrickson DS. Estimation of the concentration of low-density lipoprotein cholesterol in plasma, without use of the preparative ultracentrifuge. Clin Chem 1972;18:499-502.

16. Seidell JC, Cigolini M, Deslypere JP, et al. Body fat distribution in relation to physical activity and smoking habits in 38-year-old European men. The European Fat Distribution Study. Am J Epidemiol 1991;133:257-65.

17. Williamson DF, Madans J, Anda RF, et al. Smoking cessation and severity of weight gain in a national cohort. $N$ Engl J Med 1991;324:739-45.

18. Shukla HC, Gupta PC, Mehta HC, et al. Descriptive epidemiology of body mass index of an urban adult population in western India. $J$ Epidemiol Community Health 2002;56:876-80.

19. Bradley DP, Johnson LA, Zhang Z, et al. Effect of smoking status on total energy expenditure. Nutr Metab (Lond) 2010;7:81.

20. Karakas $P$, Bozkir MG. Anthropometric indices in relation to overweight and obesity among Turkish medical students. Arch Med Sci 2012;8:209-13.

21. Barrett-Connor E, Khaw KT. Cigarette smoking and increased central adiposity. Ann Intern Med 1989;111:783-7.

22. Shimokata H, Muller DC, Andres R. Studies in the distribution of body fat. III. Effects of cigarette smoking. JAMA 1989;261:1169-73.

23. Kim JH, Shim KW, Yoon YS, et al. Cigarette smoking increases abdominal and visceral obesity but not overall fatness: an observational study. PLOS ONE 2012;7:e45815

24. Clair C, Chiolero A, Faeh D, et al. Dose-dependent positive association between cigarette smoking, abdominal obesity and body fat: cross-sectional data from a population-based survey. BMC Public Health 2011;11:23. 
25. Caks T, Kos M. Body shape, body size and cigarette smoking relationships. Int J Public Health 2009;54:35-9.

26. Molarius A, Seidell JC, Kuulasmaa K, et al. Smoking and relative body weight: an international perspective from the WHO MONICA Project. Int J Public Health 1997;51:252-60.

27. Killen JD, Fortmann SP, Telch MJ, et al. Are heavy smokers different from light smokers? A comparison after 48hours without cigarettes. JAMA 1998;260:1581-5.

28. Baumert J, Ladwig KH, Ruf $\mathrm{E}$, et al. Determinants of heavy cigarette smoking: are there differences in men and women? Results from the population-based MONICA/KORA Augsburg surveys. Nicotine Tob Res 2010;12:1220-7.

29. Chiolero A, Jacot-Sadowski I, Faeh D, et al. Association of cigarettes smoked daily with obesity in a general adult population. Obesity (Silver Spring) 2007;15:1311-18.

30. Chiolero A, Wietlisbach V, Ruffieux C, et al. Clustering of risk behaviors with cigarette consumption: a population-based survey. Prev Med 2006;42:348-53.

31. Oh HS, Seo WS. The compound relationship of smoking and alcohol consumption with obesity. Yonsei Med J 2001;42:480-7.

32. Wietlisbach V, Marques-Vidal P, Kuulasmaa K, et al. The relation of body mass index and abdominal adiposity with dyslipidemia in 27 general populations of the WHO MONICA Project. Nutr Metab Cardiovasc Dis 2013;23:432-42.

33. Eliasson B, Attvall S, Taskinen MR, et al. The insulin resistance syndrome in smokers is related to smoking habits. Arterioscler Thromb 1994;14:1946-50.

34. Bornemisza P, Suciu I. Effect of cigarette smoking on the blood glucose level in normals and diabetics. Med Interne 1980;18:353-6.

35. Willi $\mathrm{C}$, Bodenmann $\mathrm{P}$, Ghali WA, et al. Active smoking and the risk of type 2 diabetes: a systematic review and meta-analysis. JAMA 2007;298:2654-64.

36. Handel AE, Williamson AJ, Disanto $G$, et al. Smoking and multiple sclerosis: an updated meta-analysis. PLOS ONE 2011;6:e16149.

37. Smith MR, Kinmonth AL, Luben RN, et al. Smoking status and differential white cell count in men and women in the EPIC-Norfolk population. Atherosclerosis 2003;169:331-7.

38. Ruggiero C, Metter EJ, Cherubini A, et al. White blood cell count and mortality in the Baltimore Longitudinal Study of aging. J Am Coll Cardiol 2007;49:1841-50.

39. Bolton-Smith $\mathrm{C}$, Woodward M, Tunstall-Pedoe $\mathrm{H}$, et al. Accuracy of the estimated prevalence of obesity from self reported height and weight in an adult Scottish population. J Epidemiol Community Health 2000;54:143-8. 